\title{
Influence of Degree of Saturation in the Electric Resistivity-Hydraulic Conductivity Relationship
}

\author{
Mohamed Ahmed Khalil1,2 and Fernando A. Monterio Santos ${ }^{1}$ \\ 1Universidade de Lisboa, Centro de Geofísica da Universidade de Lisboa-IDL, \\ ${ }^{2}$ National Research Institute of Astronomy and Geophysics, \\ 1 Portugal \\ ${ }^{2}$ Egypt
}

\section{Introduction}

The relationship between hydraulic conductivity and electric resistivity is one of the most difficult and challenging approaches in the field of hydrogeophysics. The promising side of this relation is the analogy between electric current flow and water flow, whereas the grand ambiguity is the non-dimensionality between both two quantities. Relationship between hydraulic conductivity and electric resistivity either measured on the ground surface or from resistivity logs, or measured in core samples has been published for different types of aquifers in different locations. Generally, these relationships are empirical and semiempirical, and confined in few locations. This relation has a positive correlation in some studies and a negative in others. So far, there is no potentially physical law controlling this relation, which is not completely understood. Eelectric current follows the path of least resistance, as do water. Within and around pores, the model of conduction of electricity is ionic and thus the resistivity of the medium is controlled more by porosity and water conductivity than by the resistivity of the rock matrix. Thus, at the pore level, the electrical path is similar to the hydraulic path and the resistivity should reflect hydraulic conductivity. This chapter will discuss the following items:

1. A general revision of the theoretical relation between hydraulic conductivity and electric resistivity and the role of surface conductance as an effective transporting mechanism.

2. A brief revision of different published theoretical and empirical methods to estimate hydraulic conductivity from electric resistivity.

3. Studying the effect of degree of groundwater saturation in the relation between hydraulic conductivity and electric resistivity via a simple numerical analysis of Archie's second law and a simplified Kozeny-Carman equation.

Initially, every hydrogeologic investigation requires an estimate of hydraulic conductivity (K), the parameter used to characterize the ease with which water flows in the subsurface. (J.J. Butler, 2005). Hydraulic conductivity differs significantly from permeability, where hydraulic conductivity of an aquifer depends on the permeability of the hosting rock and viscosity and specific weight of the fluid (Hubbert, 1940), where as permeability is a function of pore space only. 
Hydraulic conductivity has been measured long time by traditional hydrogeologic approaches. Such these approaches are: pumping test, slug test, laboratory analysis of core samples, and geophysical well logging.

Pumping tests do produce reliable $(\mathrm{K})$ estimates, but the estimates are large volumetric averages. Laboratory analysis can provide information at a very fine scale, but there are many questions about the reliability of the $(K)$ estimates obtained with those analyses. Although the slug test has the most potential of the traditional approaches for detailed characterization of $(\mathrm{K})$ variations, most sites do not have the extensive well network required for effective application of this approach. (J.J. Butler, 2005). However, these traditional methods are time-consuming and invasive.

Another group of hydrogeological methods are used to measure vertical hydraulic conductivity such as: Dipole- Flow test (DFT), Multilevel slug test (MLST), and Borehole Flow meter test (BFT). These techniques can only be used in wells, which often must be screened across a relatively large portion of the aquifer and provide information about conditions in the immediate vicinity of the well in which they are used.

The ability to reliably predict the hydraulic properties of subsurface formations is one of the most important and challenging goals in hydrogeophysics, since in water-saturated environments, estimation of subsurface porosity and hydraulic conductivity is often the primary objective. (D. P. Lesmes and S. P. Friedman, 2005). Many hydrogeophysical approaches have been used to study the relationship between hydraulic conductivity from surface resistivity measurements.

\section{Electric resistivity-hydraulic conductivity relationship}

Since the electrical resistivity of most minerals is high (exception: saturated clay, metal ores, and graphite), the electrical current flows mainly through the pore water. According to the famous Archie law (Archie, 1942), the resistivity of water saturated clay-free material can be described as

$$
R_{o}=R_{w} \cdot F_{i}
$$

Where,

$R_{o}=$ specific resistivity of water saturated sand,

$R_{w}=$ specific resistivity of pore water,

$F_{i}=$ intrinsic formation factor.

The intrinsic formation factor $\left(F_{i}\right)$ combines all properties of the material influencing electrical current flow like porosity $\varphi$, pore shape, and digenetic cementation.

$$
F_{i}=a \cdot \varphi^{-m}
$$

Different definitions for the material constant $(\mathrm{m})$ are used like porosity exponent, shape factor, and cementation degree. Factors influencing $(\mathrm{m})$ are, e.g., the geometry of pores, the compaction, the mineral composition, and the insolating properties of cementation. The constant (a) is associated with the medium and its value in many cases departs from the commonly assumed value of one. The quantities (a) and (m) have been reported to vary widely for different formations. The reported ranges are exemplified in table (1), which is based upon separate compilations of different investigators. 


\begin{tabular}{|c|c|c|c|}
\hline Lithology & $a$ & $m$ & Author (s) \\
\hline Sandstone & $\begin{array}{l}0.47-1.8 \\
0.62-1.65 \\
1.0-4.0 \\
0.48-4.31 \\
0.004-17.7\end{array}$ & $\begin{array}{l}1.64-2.23 \\
1.3-2.15 \\
0.57-1.85 \\
1.2-2.21 \\
0.02-5.67\end{array}$ & $\begin{array}{l}\text { Hill and Milburn (1956) } \\
\text { Carothers (1968) } \\
\text { Porter and Carothers (1970) } \\
\text { Timur at al. (1972) } \\
\text { Gomez-Rivero (1977) }\end{array}$ \\
\hline Carbonates & $\begin{array}{l}0.73-2.3 \\
0.45-1.25 \\
0.33-78.0 \\
0.35-0.8\end{array}$ & $\begin{array}{l}1.64-2.1 \\
1.78-2.38 \\
0.39-2.63 \\
1.7-2.3\end{array}$ & $\begin{array}{l}\text { Hill and Milburn (1956) } \\
\text { Carothers (1968) } \\
\text { Gomez-Rivero (1977) } \\
\text { Schon (1983) }\end{array}$ \\
\hline
\end{tabular}

Table 1. Reported ranges of the Archie constants (a) and (m).

Equation (2) is called Archie's first law, where it is valid only in fully saturated clean formations (the grains are perfect insulators).

When the medium is not fully saturated, water saturation plays an important role, where the changing in degree of saturation changes the effective porosity (accessible pore space). It became Archie's second law.

$$
F_{i}=\frac{R_{o}}{R_{w}}=a \varphi^{-m} S_{w}^{-n}
$$

Where, $R_{o}$ is the formation resistivity, $R_{w}$ is the pore water resistivity, $\varphi$ is the porosity, $S_{w}$ is the water saturation, $a$ and $m$ are constants related to the rock type, and $n$ is the saturation index (usually equals 2).

Many studies concluded that Archie's law breaks down in three cases: (1) clay contaminated aquifer (Worthington, 1993, Vinegar and Waxman, 1984, Pfannkuch, 1969), (2) partially saturated aquifer (Börner, et. al., 1996, Martys, 1999), and (3) fresh water aquifer (Alger, 1966, Huntley, 1987).

In Archie condition (fully saturated salt water clean sand), the apparent formation factor equals the intrinsic formation factor (Archie, 1942). Whereas in non-Archie condition the apparent formation factor is no longer equals to the intrinsic formation factor.

Vinegar and Waxman (1984) stated that Archie's empirical equations have provided the basis for the fluid saturation calculations. In shaly sands, however, exchange counter ions associated with clay minerals increase rock conductivity over that of clean sand, and the Archie relations is no longer valid.

Huntley (1986) showed that at low groundwater salinities, surface conduction substantially affects the relation between resistivity and hydraulic conductivity and, with even low clay contents, the relation between hydraulic conductivity and resistivity becomes more a function of clay content and grain size and less dependent (or independent) of porosity.

A large number of empirical relationships between hydraulic conductivity and formation factor have been published. Figure (1), shows some inverse relations between aquifer hydraulic conductivity and formation factor, reported after Heigold, et. al., (1979) using data from Illinois, Plotnikov, et. al.,(1972) using data from Kirgiza in the Soviet Union, Mazac and Landa (1979), Mazac and Landa (1979) analyzing data from Czechoslovakia, and Worthington (1975). 


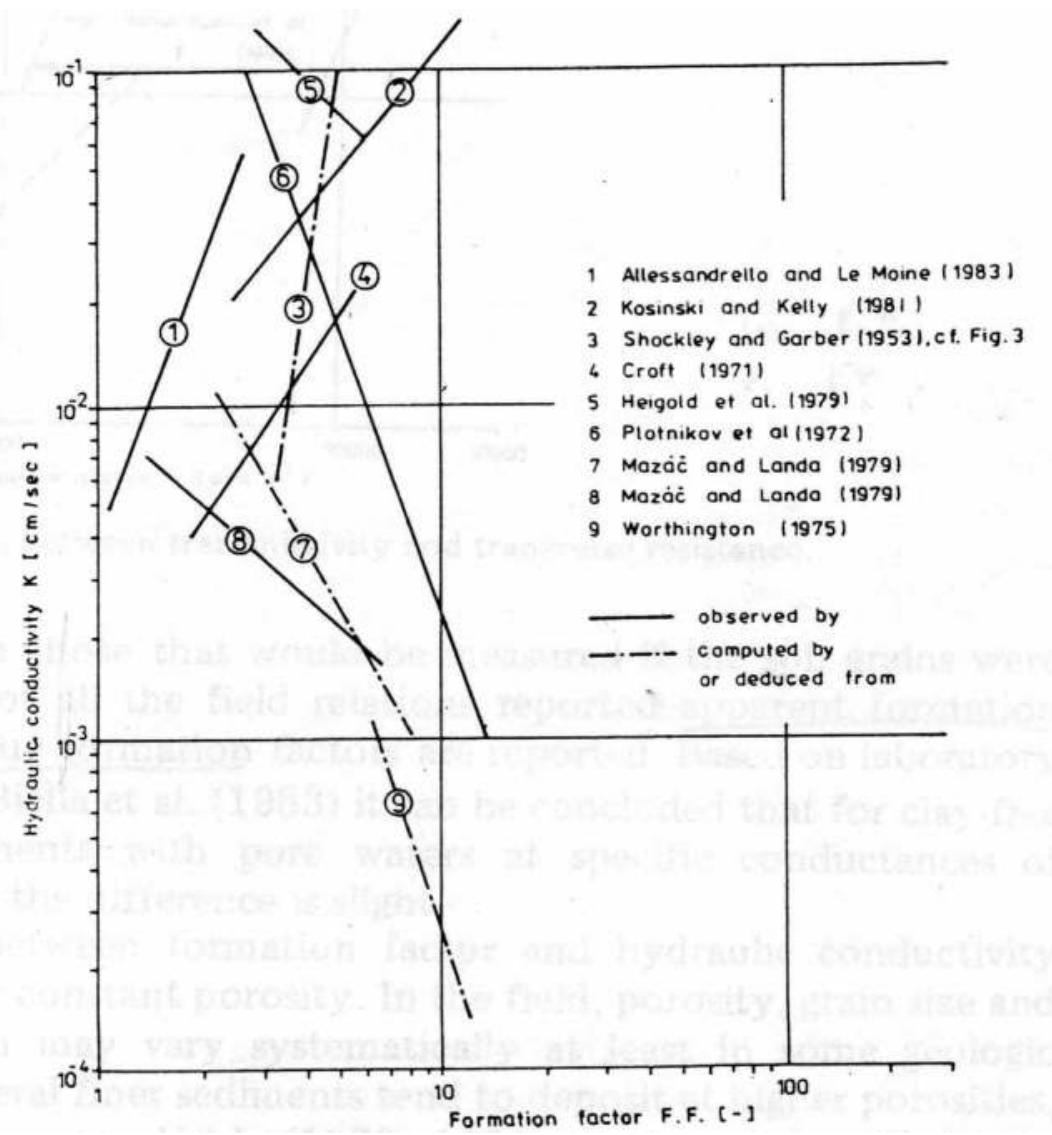

Fig. 1. Reported relation between hydraulic conductivity and aquifer formation factor (after Mazac, et. al., 1985).

Another group of case studies reported the opposite behaviour i.e., the direct relation between aquifer hydraulic conductivity and formation factor, (Allessandrello and Le Moine, 1983, Kosinski and Kelly, 1981, Shockley and Garber, 1953, and Croft, 1971).

In non-Archie conditions, there will be the double-layer phenomenon, which introduces an additional conductivity to the system called surface conductance. Surface conductance is a special form of ionic transport occurs at the interface between the solid and fluid phases of the system (Pfannkuch, 1969). It is found that, the validity of Archie's law depends on the value of the Dukhin number, which is the ratio between surface conductivity at a given frequency to the conductivity of the pore water (Bolève et al. 2007, Crespy et al. 2007). When the Dukhin number is very low with respect to 1 , Archie's law is valid.

Theoretical expressions, which include consideration of conductivity in the dispersed (solid) phase and in the continuous (fluid) phase, as well as a grain surface conductivity phase are best represented by an expression in the form of a parallel resistor model (Pfannkuch, 1969). One of the earliest parallel resistor models was proposed by Patnode and Wyllie (1950) to account for the observed effects of clay minerals in shaly sand. 


$$
\frac{1}{F_{a}}=\frac{1}{F_{i}}+\frac{R_{w}}{R_{c}}
$$

where, $R_{w}$ is the water resistivity, $R_{c}$ is the resistivity of clay minerals, $F_{i}$ is the intrinsic formation factor, and $F_{a}$ is the apparent formation factor.

Pfannkuch (1969), proposed his parallel resistor model, emphasizing the role that surface conductivity plays in the electrical transport process.

$$
\frac{1}{R_{e}}=\frac{1}{R_{f}}+\frac{1}{R_{d}}+\frac{1}{R_{s}}
$$

Or in conductance terms

$$
K_{e}=K_{f}+K_{d}+K_{s}
$$

where $K_{e}$ is the conductance of the combined or bulk phase, $K_{f}$ is the conductance of the continuous phase (fluid), $K_{d}$ is the conductance of the dispersed phase (solid), and $K_{s}$ is the surface conductance.

This model was expressed by Pfannkuch, (1969) in terms of the geometry of the matrix system, incorporating the concept of tortuosity, in the following form:

$$
F_{a}=F_{i}\left[1+\frac{K_{d}}{K_{f}} \frac{1-\varphi}{\varphi}\left(\frac{L_{e}}{L_{d}}\right)^{2}+\frac{K_{s}}{K_{f}} S_{p}\right]^{-1}
$$

Where $L_{e}$ is the tortuous path, $L_{d}$ is the flow path through the solid material, and $S_{p}$ is the specific internal pore area (the total interstitial surface area of the pores per unit por volume of the sample).

If the matrix grains consist primarily of non-conducting minerals, such as quartz, the matrix conductivity represented by the second term in the denominator of (7) becomes very small and can be neglected (Urish, 1981). Equation (7) becomes

$$
F_{a}=\frac{F_{i}}{1+\left(\frac{K_{s}}{K_{f}}\right) S_{p}}
$$

Of particular interest, the term $\left(k_{s} / k_{f}\right)$ represents the relative magnitude of the surface conductance to pore-water conductance. When $\left(k_{f}\right)$ becomes large due to high molarity concentration of fluid, this term approaches zero. The apparent formation factor $\left(F_{a}\right)$ then approaches the intrinsic formation factor $(F i)$, which is the case for saline pore-water. But for high-resistivity fresh water sands, the surface conductance effect represented by the term $\left(\frac{k_{s}}{k_{f}}\right) S_{p}$ must be considered (Urish, 1981).

This model is equivalent to Waxman-Smits model (1968) for clayey sediments. It relates the intrinsic formation factor, $F_{i}$ and the apparent formation factor, $F_{a}$ (the ratio of bulk resistivity to fluid resistivity), after taking into consideration the shale effect. According to Worthington (1993), 


$$
F_{a}=F_{i}\left(1+B Q_{v} R_{w}\right)^{-1}
$$

Waxman and Smits (1968) used two parameters; the first is $Q_{v}$, which is the cation exchange capacity (CEC) per unit pore volume of the rock (meq/ml) (Worthington, 1993). It defined as cation concentration (Butler and Knight, 1998), and reflects the specific surface area, which is a constant for a particular rock. It describes also the number of cations available for conduction that are loosely attached to the negatively charged clay surface sites. The ions, which can range in concentration from zero to approximately $1.0 \mathrm{meq} / \mathrm{ml}$, are in addition to those in the bulk pore fluid. $Q_{v}$ varies with porosity according to the following equation (Worthington, 1993).

$$
\log Q_{v}=-3.56-2.74 \log \varphi
$$

The second parameter, $B$, is the equivalent ionic conductance of clay exchange cations (mho$\mathrm{cm}^{2} / \mathrm{meq}$ ) as function of $C w$ (specific conductivity of the equilibrating electrolyte solution (mho/cm) (Worthington, 1993). This parameter is called the equivalent electrical conductance, which describes how easily the cations can move along the clay surface (Butler and Knight, 1998). It varies with water resistivity according to the equation

$$
B=3.83\left[1-0.83 \exp \left(-0.5 / R_{w}\right)\right]
$$

This equation implies that clay conduction will be more important as a mechanism than bulk pore-fluid conduction at low salinities and less important at high salinities.

The product $B Q_{v}$ has units of conductivity. Comparison between Urish model (1981) (eq.8) and Waxman-Smits model (1968) (eq.9), shows that $K f=1 / R w$, and $K s S p=B Q v$.

Equation (9) is modified by (Butler and Knight, 1998) to the following form

$$
\sigma_{b}=\varphi^{m}\left(\sigma_{w}+\frac{B Q_{v}}{S_{w}}\right) S_{w}^{n}
$$

Where, the first term in the parentheses represents bulk pore-fluid conduction, while the second represents clay surface conduction. Clay conduction is not as strongly affected by water saturation as is conduction through the bulk pore fluid because the number of clay cations remains constant until very low levels of saturation (Butler and Knight, 1998).

According to Waxman and Smits (1968) model, a shaly formation behaves like a clean formation of the same porosity, tortuosity, and fluid saturation, except the water appears to be more conductive than its bulk salinity. In other words, it says that the increase of apparent water conductivity is dependent on the presence of counter-ion (Kurniawan, 2002). Accordingly, equation (8) could be used also for shaly formations.

Vinegar and Waxman (1984) proposed a complex conductivity form of the Waxman-Smits' model (1968), based on measurements of complex conductivity $\left(\sigma^{*}\right)$ of shaly sandstone samples as function of pore water conductivity, as shown in equation (13).

$$
\sigma^{*}=\left(\frac{\sigma_{w}}{F_{a}}+\frac{B Q_{v}}{F_{i}}\right)+i \frac{\lambda Q_{v}}{F n}
$$


Where the Waxman-Smits' part of the equation is the real component that represents the electrolytic conduction in fluid $\left(\frac{\sigma_{w}}{F_{a}}\right)$ and real surface conductivity component $\left(\frac{B Q_{v}}{F_{i}}\right)$, which are in-phase with the applied electric field. The imaginary conductivity component $\left(i \frac{\lambda Q_{v}}{F n}\right)$ is the conductivity which results from displacement currents that are $90^{\circ}$ out of phase with the applied field. Vinegar and Waxman assumed that the displacement currents were caused by the membrane and the counter-ion polarization mechanisms. These two mechanisms were proportional to the effective clay content or specific surface area represented by the parameter $\left(Q_{v}\right)$. The parameter $(\lambda)$ represents an effective quadrature conductance for these surface polarization mechanisms. $(\lambda)$ is slightly dependent on salinity. The low-frequency complex conductivity $\left(\sigma^{*}\right)$ can be explained by a simple electrical parallel conduction of three components (Vinegar and Waxman 1984, Börner, 1992, Lesmes and Frye (2001)): (1) real electrolytic conductivity ( $\sigma_{\text {bulk }}$; Archie 1942), (2) real surface conductivity component $\left(\sigma_{\text {surf }}^{\prime}(\omega)\right)$, and (3) imaginary surface conductivity component $\left(\sigma_{\text {surf }}^{\prime \prime}(\omega)\right)$ caused by charge polarization.

$$
\sigma^{*}=\left[\sigma_{\text {bulk }}+\sigma_{\text {surf }}^{\prime}(\omega)\right]+i \sigma_{\text {surf }}^{\prime \prime}(\omega)
$$

The imaginary part of conductivity is widely studied by Börner et al. (1992) and (1996) and Slater and Lesmes (2002). They found a strong relation between surface conductivity components and surface-area-to-porosity ratio $\left(S_{\text {por }}\right)$, effective grain size $\left(\mathrm{d}_{10}\right)$, and the product of measured hydraulic conductivity multiplied by true formation factor $(\mathrm{K} x \mathrm{~F})$ as shown in figures $(2, a, b, c)$

Börner et al. (1992) and (1996) described the imaginary part $\left(\sigma^{\prime \prime}\right)$ of water-saturated rock as

$$
\sigma^{\prime \prime}=\frac{l f\left(\sigma_{w}\right) S_{p}}{F}
$$

where $F$, for purposes of simplicity, is the same formation factor for all conductivity components, $f\left(\sigma_{w}\right)$ is a general function concerning salinity dependence of interface conductivity and depending on surface charge density and the ion mobility, and $l$ is the ratio between real and imaginary component of interface conductivity that is assumed to be nearly independent of salinity.

Slater and Lesmes (2002) mentioned a power relationship between the saturated hydraulic conductivity and imaginary conductivity as well.

$$
K_{s}=a\left(\frac{l f\left(\sigma_{w}\right) S_{p}}{F}\right)^{b}
$$

where $a$ and $b$ are the respective constants. For the dataset they used, they find, $a=0.0002 \pm$ 0.0003 and $b=1.1 \pm 0.2\left(\sigma^{\prime \prime}\right.$ in $\mu \mathrm{S} / \mathrm{m}, \mathrm{K}$ in $\left.\mathrm{m} / \mathrm{s} ; \mathrm{R}^{2}=0.7, \mathrm{CI}=95 \%\right)$. 


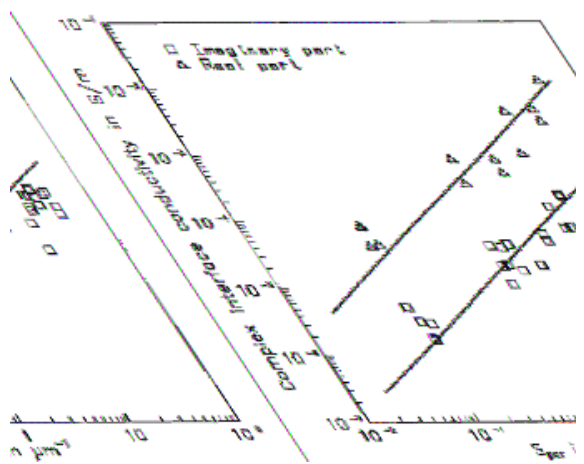

(a)

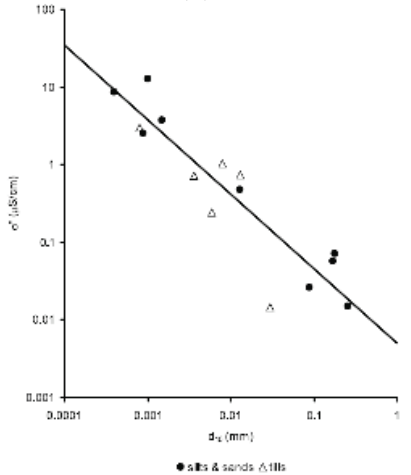

(b)

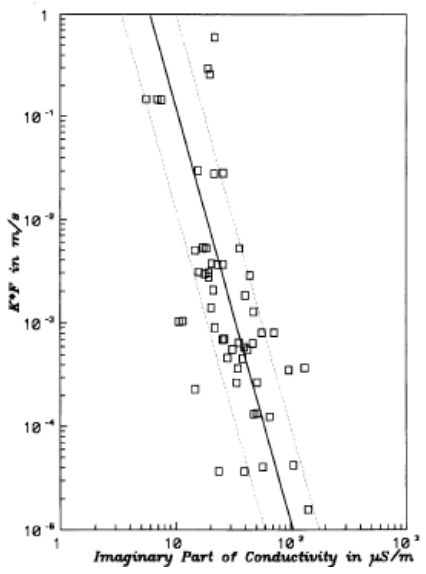

(c)

Fig. 2. (a)-Complex interface conductivity components vs. surface-area-to-porosity ratio $\mathrm{S}_{\text {por }}$ for sandstones (Börner, 1996), (b)- Plot of $\sigma_{\text {surf }}^{\prime \prime}(1 \mathrm{~Hz})$ versus (d10) (Slater and Lesmes 2002), (c)- Relationship between the imaginary component of complex electrical conductivity and the product of the true formation factor (F) and the permeability (K) (Börner, 1996). 
Börner et al $(1992,1996)$ and Slater and Lesmes (2002) showed that the imaginary (quadrature) surface conductivity resulted in nearly identical numerical values with the geometric hydraulic conductivity. It is proposed also, since there is a large similarity between imaginary surface conductivity component and real surface conductivity component, the later could be used to estimate hydraulic conductivity (Khalil and Fernando, 2010).

\section{Estimation of hydraulic conductivity from electric resistivity}

Estimation of hydraulic conductivity from electric resistivity measurements can offer the following advantages: (1) It can provide a new and important hydrogeologic trend for the application of resistivity measurements, (2) potential estimation of many hydraulic parameters through hydraulic conductivity, (3) Evaluation of the groundwater potentiality of new reclaimed areas before well drilling. It gives advantage to select the most productive zones for drilling new wells, (4) resistivity data are densely sampled, repetitive, spatially continuous information can be obtained, (5) measurements are indirect and minimally invasive, and (6) the scale of the measurement can be controlled through appropriate field survey design.

In addition to the recently developed method to estimate hydraulic conductivity from imaginary surface conductivity component via complex resistivity or induced polarisation measurements (Börner et. al. 1992, 1996, and Slater and Lesmes 2002), there are many hydrogeophysical approaches that have been used to estimate hydraulic conductivity from surface resistivity measurements. These approaches are classified as follows:

\subsection{Combined interpretation of hydrogeologic and geophysical data:}

This type of approaches is carried out by S. Niwas and D.C. Singhal (1981). These authors used Vertical electrical sounding and pumping tests to provide analytical relationship to estimate the aquifer transmissivity from transverse resistance in an area of the same geological situation, if hydraulic conductivity of the aquifer at any point therein is known, considering that (K.o) is a constant factor. This method was applied at different areas such as Umuahia area of Nigeria (P. D. Mbonu, et al, 1991), Wadi El- Assuity, Egypt (M. A. Khalil, et al, 2005) and in the middle Imo river basin aquifers, south-eastern Nigeria (A.C. Ekwe, et. al., 2006). This method resulted in a fairly good correlation with the measured data.

S. Niwas and D.C. Singhal (1985) introduced normalized aquifer resistivity instead of aquifer resistivity. An Analytical relationship between normalized transverse resistance and aquifer transmissivity has been developed for estimating transmissivity from resistivity sounding data taking into consideration the variation in groundwater quality. This method is applied by Yadav, et al, (1993) and Yadav (1995) for Jayant project, Singrauli coalfields, India. Yadav (1995) found that normalized aquifer resistivity is a very good predictor for transmissivity in this aquifer.

Chandra, S., et al., (2008) developed a similar approach to estimate hydraulic conductivity of Maheshwaram watershed aquifer in hard rock terrain in Hyderabad, India.

Another combined approach was proposed by Soupios, P., et al., (2007); they used groundwater resistivity $(\mathrm{Rw})$ measured from boreholes samples and apparent formation factor $(\mathrm{Fa})$, estimated using formation resistivity from Vertical Electrical Sounding to estimate intrinsic formation factor. Intrinsic formation factor is used to estimate porosity. Estimated porosity is then, used in Kozeny-Carman equation to estimate hydraulic conductivity of Keritis basin in Chania (Crete-Greece). 


\subsection{Empirical and semi-empirical hydrogeological and geophysical relationship depending on petrophysical relation:}

This category is the largest group of approaches in both field and laboratory scale. A) Field scale: P. F. Worthington (1976), correlated between the values of groundwater resistivity $\left(R_{w}\right)$ determined from the chemical analysis of borehole water samples, with the formation resistivity $\left(R_{o}\right)$ as deduced from the interpretation of geoelectric soundings measured nearby boreholes. He concluded that, geoelectric determination of groundwater salinity would be most exact at lower salinities and where porosity is relatively high. W. E. Kelly, (1977), carried out a correlation between resistivity values of six Schlumberger VES and pumping test data of the wells. He got a good direct relation between aquifer resistivity and measured hydraulic conductivity, good direct relation between aquifer resistivity and specific capacity, and good direct relation between formation factor and measured hydraulic conductivity. P. C. Heigold, et al., (1979), used Wenner sounding resistivity and hydraulic conductivity data from pumping test to show an inverse relation between hydraulic conductivity and resistivity due to that poorly sorted sediments are responsible for reduced porosity and thus less hydraulic conductivity. W. Kosinski and W. Kelly (1981) presented data showing a direct relation between permeability and apparent formation factor and another direct relation between transmissivity and normalized aquifer resistance. Frohlich R. and Kelly, W.E (1985), showed a direct empirical relation between hydraulic conductivity and transverse resistivity, and empirical relation between hydraulic conductivity and transverse resistivity. Mazac, et. al., (1985), studied the Factors influencing relations between electrical and hydraulic prosperities of aquifers and aquifer materials. A general hydrogeophysical model was used to demonstrate that at the aquifer scale a variety of relations might be expected. R.K. Frohlich, et. al., (1996), studied the relationship between hydraulic conductivity and aquifer resistivity in fractured crystalline bedrock, Rhode Island. Reverse relation between hydraulic conductivity and aquifer resistivity has been found. This result agree with theoretical calculations by Brown (1989), laboratory sample measurements by Mazac et al, (1990), and field data relationship by Heigold et al (1979).

B) Laboratory scale: David Huntley (1987) performed laboratory experiments to show the importance of matrix conduction. He showed that the ratio between the measured bulk resistivity and the measured fluid resistivity, the apparent formation factor varies significantly with varying fluid resistivity for the range of normal ground water salinities.

\subsection{Theoretically petrophysical based models:}

The accuracy of determining the porosity, the filtration coefficient and transmissivity of an aquiferous reservoir rock, the mineralization and actual flow velocity of underground water in a percolation medium by means of surface geoelectric methods is discussed via synthetic data (O. Mazac, et. al. 1978). The results of theoretical analysis enable the accuracy in determining the fundamental hydrogeological parameters by the VES method. R.K.Frohlich, (1994), the relationship between resistivity and hydraulic conductivity is discussed on the Kozeny- Carmen equation. The uses and abuses of the Archie equations are modelled by Worthington, (1993) using Waxman and Smits equation (1968).

Generally, geophysics assisted groundwater exploration is based on empirical relationships between electric and hydraulic units. Empirical laws are unsatisfactory, as they do not provide an understanding of any potential physical law. However, similar relationships must be established in new areas. The dependence between $(\mathrm{K})$ and $(\mathrm{R})$ remains nonunique; a simple predictable K-R relationship can not be expected. 
Some previous studies combine two or more regimes such that, D.W. Urish (1981), where, theoretically three-phase parallel resistor model, supported by data from laboratory tests assumed inverse correlation between porosity and hydraulic conductivity. From empirical and theoretical model a positive correlation between apparent formation factor and hydraulic conductivity is shown. The model demonstrates that intergranular surface conductance is an important factor at small grain size and high pore water resistivities, operating to lower the apparent formation factor. W. E. Kelly and P. F. Reiter (1984), where the influence of aquifer anisotropy caused by layering on the relation between resistivity and hydraulic conductivity was studied with idealized analytic and numerical models.

It is worthily mentioned that all these relations are site restricted and have no potentially physical law; in addition, the physical relation between hydraulic conductivity and aquifer resistivity is not completely understood. It has a direct correlation in some studies and reverses in others. The main target of this paper is to study the effect of water saturation in such relation.

\section{Influence of water saturation in the electric resistivity-hydraulic conductivity relationship.}

Archie's first and second laws show the relation between bulk resistivity and formation factor. Formation factor could be linked to hydraulic conductivity by Kozeny-Carman equation. One of the most recent modifications of this equation is made by Börner and Shön (1991). They obtained the following expression for the estimation of hydraulic conductivity of unconsolidated sediments (sand, gravel, silt) (Lesmes and Friedman, 2005):

$$
K_{s}=\frac{a}{F S_{p[e l]}^{c}}=\frac{a}{F\left(10^{5} \sigma_{1 H z}^{\prime \prime}\right)^{c}}
$$

Where $K_{s}$ is the hydraulic conductivity in $\mathrm{m} / \mathrm{s}, \mathrm{F}$ is the apparent formation factor, $S_{p[e l]}$ is the electrically estimated specific surface area per unit volume $\left(\mu m^{-1}\right), \sigma^{\prime \prime}$ is the imaginary conductivity component measured at $1 \mathrm{~Hz}(\mathrm{~S} / \mathrm{m})$, a is a constant equals $10^{-5}, \mathrm{C}$ is a constant ranges between 2.8 and 4.6 depending on the material type and the method used to measure Ks.

Accordingly, the modified Kozeny-Carman equation (Eq. 17) and Archie's first and second laws (Eqs. (2) and (3)) should control the relationship between hydraulic conductivity (K) and formation resistivity $\left(R_{\circ}\right)$ in both saturated and non-saturated sediments.

Khalil and Fernando (2009) numerically analyzed two important equations: (1) Archie's second (eq.3), which controls the relation between porosity, water saturation, and formation factor, (2) Kozeny-Carman model (eq.17), which controls the relation between formation factor and hydraulic conductivity. Beginning with the generalized Archie's second law, using $\mathrm{a}=1, \mathrm{~m}=\mathrm{n}=2$, and proposed values of porosity and water saturation ranging from 0.2 to 1 with an increment of 0.2 . They calculated the net product of porosity $(\varphi)$ and water saturation $\left(S_{w}\right)$, which is the volumetric water content $(\theta)$.

$$
\theta=\varphi \cdot S_{w}
$$

Figure $(3, a)$ shows the relation between intrinsic formation factor and porosity when water saturation equals one. Figure $(3, b)$ shows the same relation when porosity equals water saturation. The two cases (Fig 3, a, b) resulted in an inverse power relationship with a correlation coefficient equals one. 


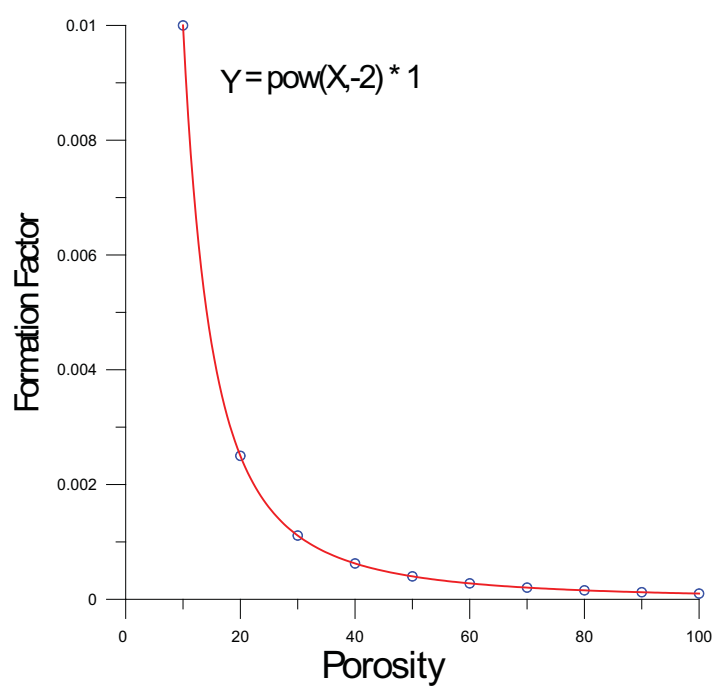

(a)

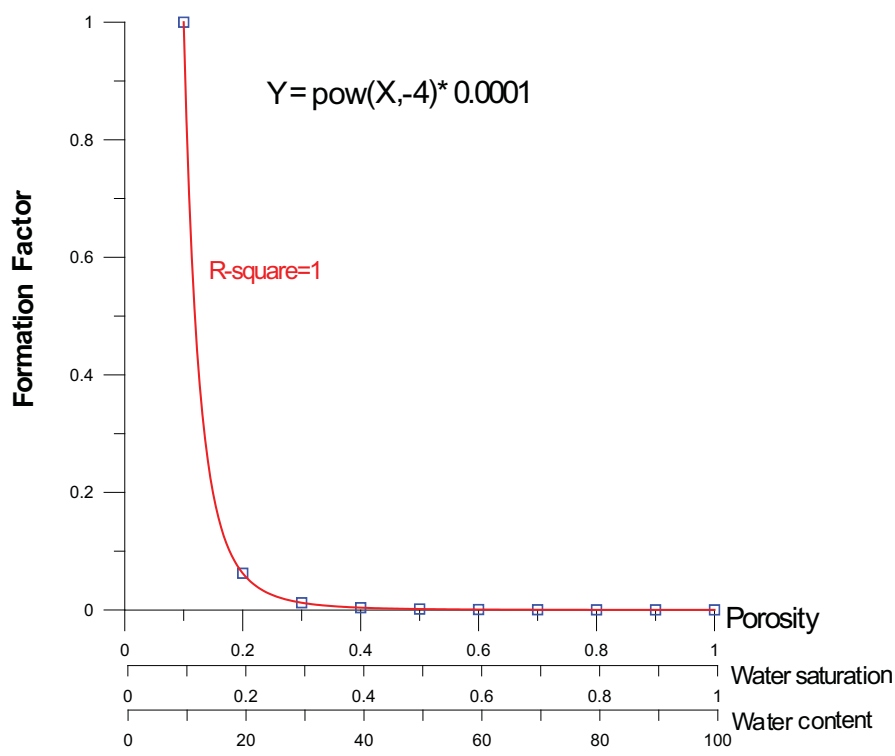

(b)

Fig. 3. Analytical relation between formation factor, porosity, water saturation, and water content when A)-water saturation =1, and B) - porosity = water saturation.

In the case where water saturation and porosity changes inversely to each other, they got the following relation (Fig.4) 


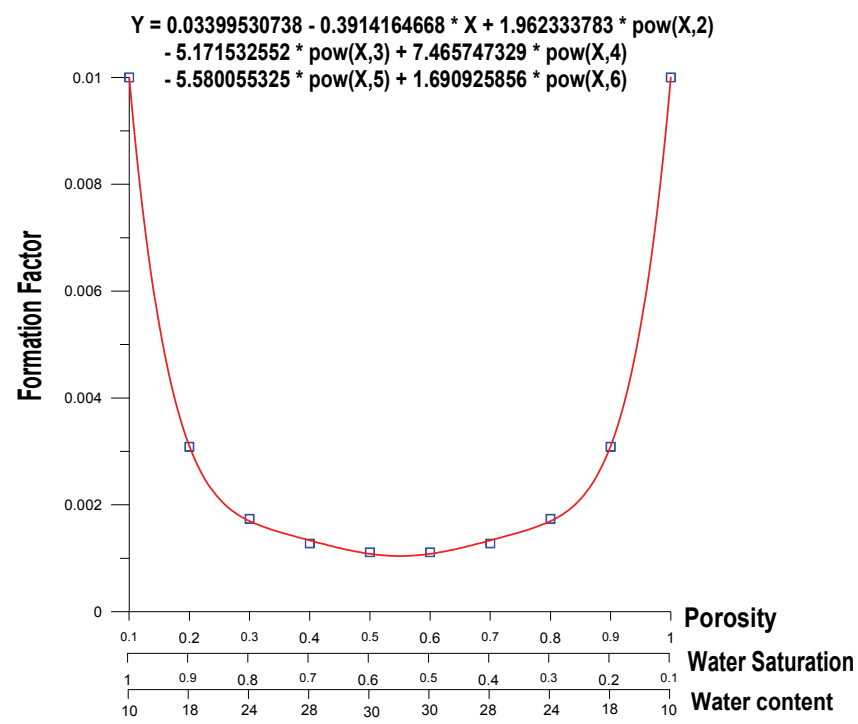

Fig. 4. Analytical relationship between Formation factor, porosity, water saturation and water content when porosity $\neq$ water saturation.

Archie's law in this case has deviated from it is traditional power low to a polynomial correlation of sixth order. In the right half of the curve, where porosity is lower than water saturation, and lower than $50 \%$, a considerable inverse polynomial relation has achieved. In the left half of the curve, where porosity is higher than water saturation, and higher than $50 \%$ (poorly saturated sediments) a direct polynomial relation exist. In this part of the curve Archie's second low does not deviated from its power low to a polynomial correlation only but it breaks down also, where formation factor has a direct correlation with porosity and water saturation. However, for practical purposes, a direct correlation between $(F)$ and $(\varphi)$ is in common usage (Börner, et. al., 1996). Martys, (1999) used Lattice Boltzmann method to numerically simulate the diffusive transport of ions in two classes of partially-saturated porous media as a function of saturation and wetting properties. At high saturations, good agreement is found between his estimates of diffusivity and that predicted by the semiempirical Archie's second law. At lower saturations, it is found that Archie's second law breaks down as percolation effects become important. His study resulted in an empirical polynomial function between relative diffusivity $\left(\frac{\sigma_{b i}}{\sigma_{b}}\right)$ and water saturation $(\mathrm{Sw})$, where $\sigma_{b i}$ is the electrical conductivity of fluid and $\sigma_{b}$ the electrical conductivity of wetted (partially saturated) porous material.

Since, figure (4) describes two different hydrogeological media; they are separated and presented in figures $(5 a$, and $b)$.

Figure (5) describes the relation when water saturation $>50 \%>$ porosity (5.a) and when water saturation $<50 \%<$ porosity (5.b). The best fit to the analytical data (correlation coefficient $=1$ ) is the polynomial regression fourth order (blue line), where power correlation shows a lower fitting (red line) in the two cases. Figure $(5$, a) still reflect the inverse relation between intrinsic formation factor and both porosity and water saturation. 


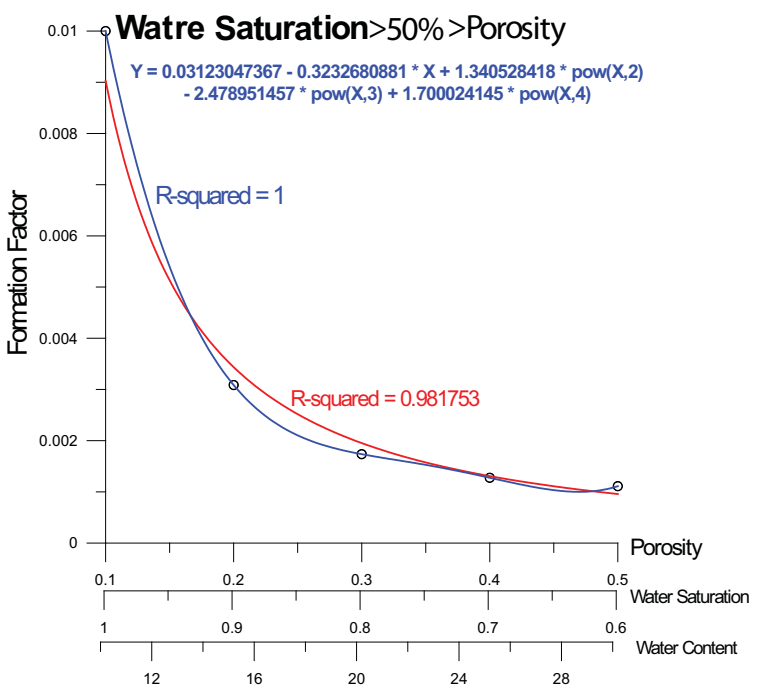

(a)

\section{Waetr Saturation $<50 \%<$ Porosity}

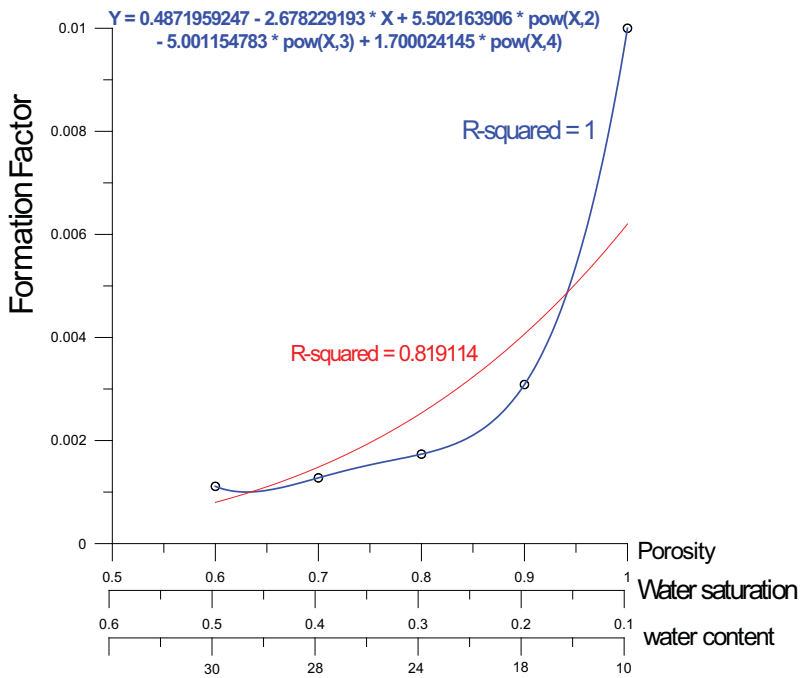

(b)

Fig. 5. Analytical relationship between Formation factor, porosity, water saturation and water content in the two different cases.

Whereas figure $(5, b)$ reflects a direct correlation between intrinsic formation factor and both porosity and water saturation, which is in agreement with Martys, (1999) and (Börner, 1996). Applying these direct and inverse relations in the modified Kozeny-Carman model (Eq. 4), resulted in an inverse correlation between hydraulic conductivity and formation factor in the first case (fig.5, a) and a direct correlation in the second case (fig 5, b). Comparing these 
results with some published empirical relations concluded between aquifer hydraulic conductivity from pumping test and formation factor, shows an agreement (Fig.1).

In the view of present analysis (Figs, 3, 4, and 5), we can expect a group of relations between hydraulic conductivity (K) and formation resistivity (Ro), differ in mathematical expressions and hence in curve form. These relations could be classified into 3 characteristic cases:

1. An inverse power relation in fully saturated aquifers and when porosity equals water saturation.

2. An inverse polynomial relation in unsaturated aquifers, when water saturation higher than $50 \%$, higher than porosity.

3. A direct polynomial relation in poorly saturated aquifers, when water saturation lower than $50 \%$, lower than porosity.

In the next section, the present results are compared with some previously published empirical relations between aquifer resistivity and hydraulic conductivity in different geographic locations and hydrogeologic conditions with a comparison between expected porosity and saturation from our models with that measured, as possible as the data is available.

\subsection{First category :( fully saturated aquifer or water saturation equals porosity)}

Two case studies (Fig.6, a and b) are collected: (A) fractured crystalline bedrock, central landfill, Rhode Island, USA (Frohlich, et. al., 1996), (B) Granitic host rock, (OUC), Hyderabad, A.P., India (K.P.Singh, 2005).

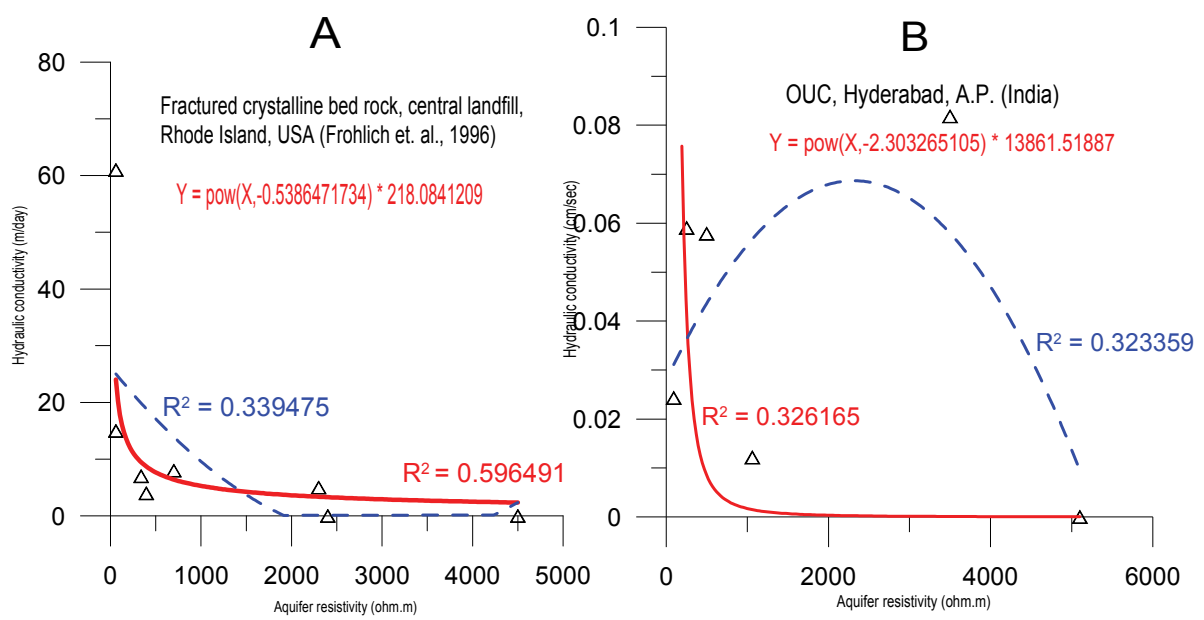

Fig. 6. Empirical relationship between hydraulic conductivity and aquifer resistivity in different locations. (Red sold line is the power relation; blue dashed line is the polynomial relation)

A considerable inverse power correlation between hydraulic conductivity and aquifer resistivity exist in the two case studies. The correlation coefficient of the power relation is higher than that of polynomial in the two cases. Geologically, all cases are from fractured hard rock aquifers. The fractured crystalline bedrock, central landfill, Rhode Island, USA (fig.6-A) is characterized by high fractured granite, high hydraulic conductivity, no primary permeability and hydraulic flow is restricted to fractures, and no clay, where weathering product of granite decomposition, have been washed out by glacial melt waters (Frohlich, 
et. al., 1996). Water resistivity ranges from 41 to 125 Ohm.m (Frohlich, et. al., 1996). Estimated porosity from the published data of formation resistivity (Ro), water resistivity $(\mathrm{Rw})$, and formation factor $(\mathrm{F})$ ranges from 19 to $82 \%$, assuming that $\mathrm{a}=1$ and $\mathrm{m}=2$, in Archie's first law.

Data published by K.P.Singh, (2005) were measured in Osmania University Campus (OUC), Hyderabad A.P. (India) for the fractured Granitic aquifer of Archaean age.

The available information of the two fractured hard rock aquifers and the empirical inverse power correlation indicate that they are in a good agreement with the first analytical model (fig.3).

\subsection{Second category (water saturation $>50 \%>$ porosity)}

Three case studies have non-linear inverse correlation between hydraulic conductivity and formation resistivity: Glacial outwash aquifer in central Illinois, USA, (Heigold, et. al., 1979), Banda area U.P., India, (Niwas and Singhal, 1985), and Mount Tsukuba, Central Japan, intact rock aquifer (Sudo et. al., 2004).

From Figure (7), the data are correlated as inverse polynomial with more correlation coefficient than that of power correlation, which in agreement with figure $(5, \mathrm{~A})$.
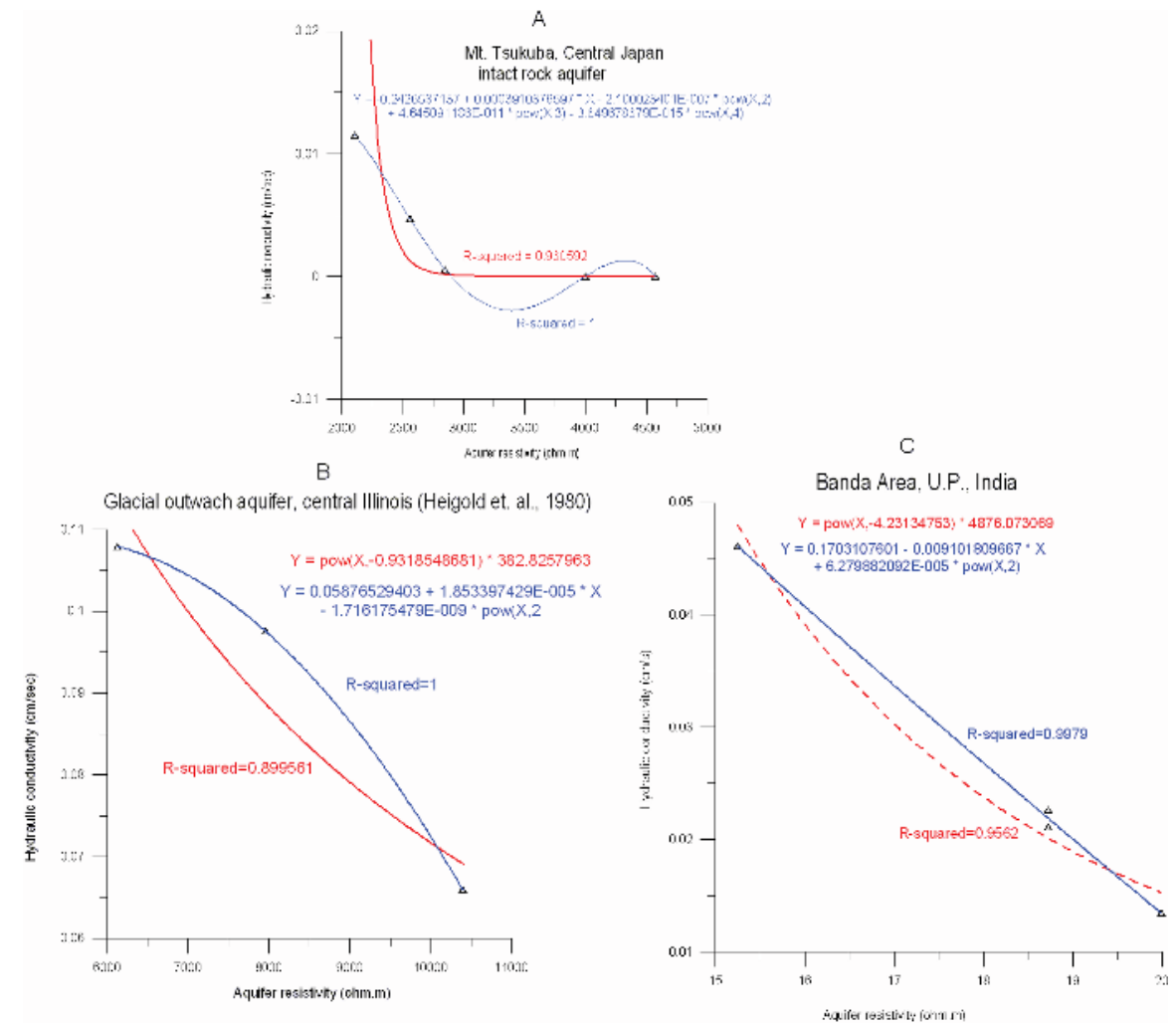

Fig. 7. Empirical relationship between hydraulic conductivity and aquifer resistivity in different locations. (Red dashed line is the power relation; blue solid line is the polynomial relation). 
As for Glacial outwash aquifer in central Illinois, USA, (Heigold, et. al., 1979), the explanation of this inverse relation was a problematic. Because Kelly (1977) found a direct linear relationship between hydraulic conductivity and resistivity of the water bearing deposits in two New England aquifers composed of the same glacial deposits of sand and gravel and one case study of direct relation in glacial deposits is discovered later by Frohlich and Kelly (1985). The inverse correlation was reasoned due to more poorly sorted sediments near the head of the Niantic-Illiopolis aquifer, which are responsible not only for reduced porosity and thus less hydraulic conductivity, but also for an increase in the volume of low conductivity solids which increase the resistivity of the aquifer (Heigold et. al., 1979). Kelly et al, (1984) explained the inverse relation due to the presence of clay, although the clay fraction of the aquifer was quite small (less than 4\%) (Heigold et. al., 1979). Frohich, (1994) explained this inverse relation due to; they have only three data points.

Heigold et. al., (1979) in his paper, measured the porosity of these three samples; they are $26 \%, 32 \%$, and $39 \%$. Sieve analysis made on each sample indicates that the clay fraction of the aquifer was quite small (less than $4 \%$ ). Water resistivity is $1818 \mathrm{ohm} . \mathrm{cm}$, and total dissolved solids are $490 \mathrm{ppm}$. All mentioned parameters of this aquifer are in agreement with our approach in particular the porosity values. The Mount Tsukuba, Central Japan, intact rock aquifer is covered by homogeneous and fine-grained granite of late Cretaceous to early Palaeogene age. The relation between resistivity and hydraulic conductivity is based on electrical logging and in-situ permeability data from boreholes (Sudo et. al., 2004).

Concerning Banda area U.P., India, the presence of hard rock lithologies in the area may be the cause the negative correlation of the variation in permeability with resistivity (Singh, 2005). This type of inverse correlation typically is found in saturated fractured hard rock aquifer, as previously discussed, but the polynomial correlation is attributed to dissimilarity between porosity and water saturation.

\subsection{Third category (water saturation $<\mathbf{5 0 \%}<$ porosity)}

This category contains one case study for weathered hard rock aquifer is in Mt.Tsukuba, Central Japan, (Sudo, et. el. 2004).

Hydraulic conductivity of this aquifer has an ideal fourth order polynomial direct correlation with the aquifer resistivity (Fig.8). The correlation coefficient of polynomial relation (in blue) is higher than power relation (in red). The mathematical characteristics of this sample classify it in the third category of our analytical models (Fig.5-B), where porosity is higher than $50 \%$, higher than water saturation. The category highlights on the effect of low saturation on the relation between hydraulic conductivity and resistivity of porous media, where in low saturation conductivity of the electrical double layer increases, and surface conductance becomes the main transport mechanism (Pfannkuch, 1969, Urish, 1981, Brovelli, et al., 2005).

The data of Mt. Tsukuba, central Japan weathered rock aquifer are sampled from finegrained Granitic rocks with cracks. The cracks have approximately 2-mm-thick fillings (Sudo, et. el. 2004). It is worthily to mention that, the resistivity and hydraulic conductivity data of Mount Tsukuba, Central Japan, in both intact and weathered rock aquifer reflect perfectly the analytical relation in the form of polynomial forth orders. This is may reasoned to the nature of the data, where resistivity data are extracted from resistivity log, and permeability data are from in-situ permeability measurements (Sudo, et. el. 2004). It is important to mention that such direct relation between hydraulic conductivity and aquifer 


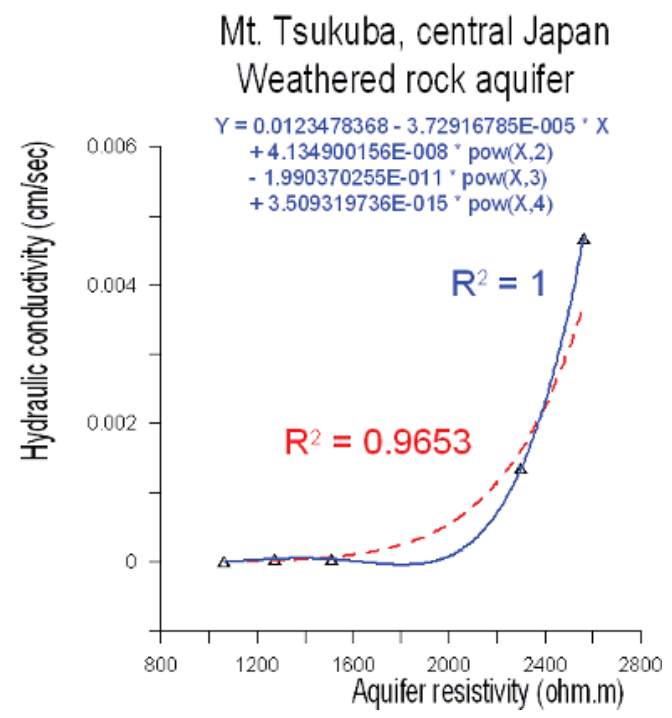

Fig. 8. Empirical relationship between hydraulic conductivity and aquifer resistivity in Mt. Tsukuba, central japan (Red dashed line is the power relation; blue solid line is the polynomial relation).

resistivity could be resulted also in case of high clay content and/or high groundwater resistivity aquifers, where surface conductance effect resulted on the surface of clay mineral or sand imbedded in fresh water became the main transport mechanism, and Archie's low in these cases breaks down (Huntley, 1987, Alger, 1966, Worthington, 1993, Vinegar and Waxman, 1984, Pfannkuch, 1969).

\section{Conclusion}

Studying the relationship between hydraulic conductivity and electrical resistivity is one of the most interesting objects in both geophysics and hydrogeology. Hydrogeological methods still have some disadvantages, and the measured hydraulic conductivity value is a function of the measuring method. Geophysical methods as well still empirical and site restricted. Hydraulic conductivity and electric resistivity relationship showed a positive non-linear relation in some studies and a negative non-linear relation in others. This is attributed to the relation between apparent formation factor, which is directly proportional to the bulk resistivity, and the intrinsic formation factor, which is inversely proportional to porosity. When the hydrogeological system is in agreement with Archie's conditions (fully saturated, free of clay, high salinity water), the apparent formation factor is equivalent to intrinsic formation factor, and any relation between hydraulic conductivity and bulk resistivity should depends on the porosity. In the other side, when the hydrogeological system disagrees with Archie's conditions, the apparent formation factor is not longer equivalent to intrinsic formation factor. Any relation between hydraulic conductivity and bulk resistivity in this case should depend on surface conductance effect, which is a function of grain size and the specific surface area of the grains. An analytical approach has been illustrated here to show the effect of water saturation on the electric resistivity-hydraulic 
conductivity relationship. The results are categorized into three non-linear relations. Some field scale relationships empirically support the present analytical approach.

\section{References}

Alger RP (1966) Interpretation of electric logs in fresh water wells in unconsolidated formations, Soc of Prof Well Log Analyst Trans, Art CC, 1-25.

Archie GE (1942) The electrical resistivity $\log$ as an aid in determining some reservoir characteristics. American Institute of Mineral and Metal Engineering. Technical publication, 1442, Petroleum Technology, pp. 8-13.

Batu, V., 1998. Aquifer Hydraulics; A Comprehensive Guide to Hydrogeologic Data Analysis. John Wiley \& Sons, Inc. New York, NY.

Bear, J., (1972). Dynamics of Fluids in Porous Media. American Elsevier. New York, NY.

Börner FD, (2006) Complex conductivity measurements. In Kirsch R (ed) Groundwater geophysics: a tool for hydrogeology. ISBN 13 978-3-540-29383-5 Springer Berlin Heidelberg New York.

Börner FD, Schopper JR, Weller A (1996) Evaluation of transport and storage properties in the soil and groundwater zone from induced polarization measurements. Geophys Prospect 44:583-601. doi: 10.1111/j.1365-2478.1996.tb00167.x

Börner, F. D., and J. H. Schön, (1991) A relation between the quadrature component of electrical conductivity and the specific surface area of sedimentary rocks, Log Anal., 32: 612-613.

Brown, S. R., (1989) Transport of fluid and electric current through a single fracture. Journal of Geophysical research, 94 (37): 9429-9438.

Butler, D. B., and Knight, R. J. (1998) Electrical conductivity of steam-flooded, clay-bearing geologic materials. GEOPHYSICS, V. 63, No. 4, P. 1137-1149.

Butler, J. J. (2005) Hydrogeological methods for estimation of spatial variations in hydraulic conductivity. (In Hydrogeophysics, p.23-58.).

Carman, P. C., 1937. Fluid flow through granular beds. Transactions, Institution of chemical engineers, London, 15: 150466.

Carman, P. C., 1956. Flow of gases through porous media. Butter worth, London.

Carothers JE (1968) A statistical study of the formation factor relation. Log Anal 9(5):13-20

Chandra, S., Ahmed, S., Ram, A., and Dewandel B. (2008) Estimation of hard rock aquifers hydraulic conductivity from geoelectrical measurements: a theoretical development with field application. Journal of Hydrology, V. 357, I. 3-4, P.218-227, doi:10.1016/j.jhydrol.2008.05.023

Chappelier, D., 1992. Well logging in hydrogeology. A.A.Balkema Publishers, 175p.

Chapuis, R. P. and Aubertin, M., 2003. Predicting the coefficient of permeability of soils using the Koneny-Carman equation. EPM-RT2003-03. department CGM, Ecole polytechnique de Montrial. Canada.

Deppermann, K. (1954) Die Abhangikeit des scheinbaren Widerstandes vom Sonden abstand bei der vierpunkt-Methode, Geophysical prospecting, II : 262-273.

Ekwe AC, Onu NN, Onuoha KM (2006) Estimation of aquifer hydraulic characteristics from electrical sounding data: the case of middle Imo River basin aquifers, south-eastern Nigeria. J Spatial Hydrol 6(2):121-132

Evans, K., Beavan, J., Simpson, D., 1991. Estimating aquifer parameters from analysis of forced fluctuation in well level: An example from the Nubian Formation near Aswan, Egypt, 1. Hydrogeological background and large-scale permeability estimates. Journal of Geophysical Research. 96, B7, 12.127-12.137. 
Frohlich R. K and Kelly W. E. (1985) the relation between hydraulic transmissivity and transverse resistance in a complicated aquifer of glacial outwash deposits. Journal of hydrology. 79 (3-4): 215-229.

Frohlich, R. K., (1994) The electric- hydraulic relationship. A geophysical model. Trends in hydrogeology. $1: 347-358$.

Frohlich, R. K., Fisher, J. J. and E. Summerly (1996) Electric-hydraulic conductivity correlation in fractured crystalline bedrock: Central Landfill, Rhode Island, USA. Journal of Applied Geophysics 35: 249-259.

Gerasimos A. T. (1985) A study of the hydrogeophysical properties of fissured aquifers using a double porosity model. Journal of Hydrology, 78 (1985) 331-344, 0022$1694 / 85 / \$ 03.30$

Gomez-Rivero O (1977) some considerations about the possible use of the parameters a and $\mathrm{m}$ as a formation evaluation tool through well logs. Trans SPWLA 18th Ann Logging Symp: J 1-24

Heigold, P. C., Gilkeson, R. H., Cartwright, K. and Reed, P. C. (1979) Aquifer transmissivity from surficial electrical methods. Ground water, 17 (4) :338-345.

Hill, H.J. and Milburn, J.D., (1956) Effect of clay and water salinity on electrochemical behaviour of reservoir rocks. Trans. AIME, 207: 65-72.

Hubbert, M. King (1940) The theory of groundwater motion. Journal of Geology. 48 (8): 785944.

Huntley, D. (1987) Relations between permeability and electrical resistivity in granular aquifers. Ground water. 24 (4): 466-474.

Kallergis, G., 1999. Applied-Environmental Hydrogeology. Technical Chamber of Greece, Athens, p. 330.

Kelly, W. E, and Reiter, P., (1984) Influence of Anisotropy on relations between electrical and hydraulic properties of aquifers. Journal of Hydrology 74: 311-321.

Kelly, W.E. (1977) Geoelectric sounding for estimating aquifer hydraulic conductivity. Groundwater. 15 (6) : 420-425.

Khalil MA, Abd-Alla MA (2005) An approach to estimate hydraulic parameters and water quality from surface resistivity measurements at wadi El-Assuity area, Egypt. NRIAG J Geophys, Special issue: 267-281

Khalil, MA and Santos, FA (2009) Influence of degree of saturation in the electric resistivityhydraulic conductivity relationship. Surveys in Geophysics. 30:601-615. DOI $10.1007 /$ s10712-009-9072-4

Khalil, M. and Fernando M. (2010): Real surface conductivity component: an approach to estimating hydraulic conductivity for fresh water aquifers characterised with clean sand, (submitted to Journal of hydrology).

Kim, J., Sultan, M., 2002. Assessment of the long-term hydrologic impacts of Lake Nasser and related irrigation projects in southwestern Egypt, Journal of Hydrology, 262, 68-83.

Kim, J., Sultan, M., 2002. Assessment of the long-term hydrologic impacts of Lake Nasser and related irrigation projects in southwestern Egypt, Journal of Hydrology, 262, 68-83.

Kirsch, R., (ed.) (2006) Groundwater Geophysics, Springer.

Kosiniski, W.K and Kelly, E.W. (1981) Geoelectrical sounding for predicting aquifer properties. Groundwater. 19: 163-171.

Kozeny, J. 1927. Ueber Kapillare leitung des wassers in Boden. Sitzungsber Akad. Wiss., Wein, 136 (2a): 271-306.

Krahl, J., Kauffmann, G., Kozur, H., Richter, D., Forster, O., Heinritzi, F., (1983). Neue Daten zur Biostratigraphie und zur tektonischen Lagerung der Phyllit-Gruppe und der Trypali- Gruppe aufder Insel Kreta (Griechenland). Geol. Rundsch. 72, 1147-1166. 
Kurniawan (2002) Evaluation of the hydrocarbon potential in low-salinity shaly sand MSc thesis, Faculty of the Louisiana State University and Agricultural and Mechanical College.pp. 86.

Lee Slater (2007) Near Surface Electrical Characterization of Hydraulic Conductivity: From Petrophysical Properties to Aquifer Geometries-A Review. Surveys in Geophysics. 28:169-197.

Lesmes, D. P. and Friedman, S. P. (2005) Relationships between the electrical and hydrogeological properties of rocks and soils, (in Hydrogeophysics :87-128.)

Lorne, B., Perrier, F., and Avouac, J. (1999) Streaming potential measurements,2. Relationship between electrical and hydraulic flow patterns from rock samples during deformation. JOURNAL OF GEOPHYSICAL RESEARCH, V. 104, NO. B8, P. 17,879-17,896. 0148-0227/99/1999JB900155509.00

Martys NS (1999) Diffusion in partially-saturated porous materials. Mater Struct (Materiaux et Constructions) 32:555-562

Mazac , O., Landa, I., and Skuthan, B. (1978) Information capacity of some geoelectrical methods applied to hydrogeological survey. Proc. 23 ${ }^{\text {rd }}$ geophysical symposium, Verna, Bulgaria: 460-472.

Mazac, O., Cislerova, M., Kelly, W.E., Landa, I, and Venhodova, D., (1990) Determination of hydraulic conductivities by surface geoelectrical methods. In: ed. S. Ward, Geotechnical and Environmental Geophysics, Vol. II. Soc. Explor. Geophys: 125-131.

Mazac, O., Kelly, W., and Landa, I. (1985) A hydrogeophysical model for relations between electrical and hydraulic properties of aquifers. Journal of Hydrogeology 79: 1-19.

Mbonu PC, Ebeniro JO, Ofoegbu CO, Ekine AS (1991) Geoelectric sounding for the determination of aquifer characteristics in parts of the Umuahia area of Nigeria. Geophys 56(2):284-291

Niwas S, Singhal DC (1981) Estimation of aquifer transmissivity from Dar Zarrouk parameters in porous media. J Hydrol (Amst) 50:393-399.doi:10.1016/00221694(81) $90082-2$

Niwas S, Singhal DC (1985) Aquifer transmissivity of porous media from resistivity data. J Hydrol (Amst) 82:143-153. doi:10.1016/0022-1694(85)90050-2

Patnode, H. W., and Wyllie, M. R. (1950) the presence of condutive solids in reservoir rocks as a factor in electric log interpretation, J. Pet. Technol. , 189, 47-52.

Paul F. Worthington (1976) Hydrogeophysical equivalence of water salinity, porosity and matrix conduction in arenaceous aquifers. Groundwater $14(4): 224-232$.

Pflannkuch HO (1969) On the correlation of electrical conductivity properties of porous system with viscous flow transport coefficients. Proceedings of the IAHR First International Symposium on Fundamentals of Transport Phenomena in Porous Media, Haifa, pp. 42-54

Pflannkuch. H.O. (1969) On the correlation of electrical conductivity properties of porous system with viscous flow transport coefficients. Proceedings of the IAHR First International symposium on fundamentals of transport phenomena in porous media, Haifa : 42-54.

Porter, C.R. and Carothers, J.E, (1970) Formation factor-porosity relation derived from well log data. Trans. SPWLA11th Ann. Logging Symp: 1-19.

REGWA, 2003. Report on RML Well. The General Company for Research and Groundwater.

Rubin Y, Hubbard S (2005) Hydrogeophysics, water science and technology library, vol 50. Springer, Berlin, p 523 Schon J (1983) Petrophysik. Akademie-Verlag, Berlin

Schon, J., (1983) Petrophysik. Akademie-Verlag, Berlin, 405 pp. 
Scott, J.B. (2006) The origin of the observed low-frequency electrical polarization in sandstones. GEOPHYSICS,V. 71, NO. 5; P. G235-G238,10.1190/1.2258092

Shah, P. H. and Singh,D. N. (2005) Generalized Archie's Law for Estimation of Soil Electrical Conductivity. Journal of ASTM International, Vol.2, I.5, DOI: 10.1520/JAI13087

Singh, K. P (2003) Geo-electrical exploration for groundwater in a Hard Rock Region of Hyderabad, India, First Break, 21: 29-34.

Singh, K. P (2005) Nonlinear estimation of aquifer parameters from surfficial resistivity measurements. Hydrol.Earth Sys. Sci. Discuss., 2: 917-938.

Soupios P, Kouli M, Vallianatos F, Vafidis A, Stavroulakis G (2007) Estimation of aquifer hydraulic parameters from surficial geophysical methods: a case study of Keritis basin in Chania (Crete-Greece). J Hydrol (Amst) 338:122-131. doi:10.1016/j.jhydrol.2007.02.028

Sudo, H., Tanaka, T., Kobayashi, T., Kondo, T., Takahashi, T., Miyamoto, M., and M. Amagai, (2004) Permeability imaging in granitic rocks based on surface resistivity profiling. Exploration Geophysics 35: 56-61

Sundberg, K., (1932) Effect of impregnating waters on electrical conductivity of solids and rocks. Trans. AIME, 97: 367-391.

Telfold, W. M., Geldert. L.P. and Sheriff, R. E. (1991) Applied Geophysics. Cambridge Univ. New York.

Timur, A., Hemkins, W.B. and Worthington, A.E. (1972) Porosity and pressure dependence of formation resistivity factor for sandstones. Trans. CWLS $4^{\text {th }}$ Formation Evaluation Symp., 30pp.

Urish DW (1981) Electrical resistivity-hydraulic conductivity relationships in glacial outwash aquifers. Water Resour Res 17(5):1401-1408. doi:10.1029/WR017i005p01401

VinegarHJ, WaxmanMH(1984) Induced polarization of shaly sands. Geophysics 49(8):12671287. doi:10.1190/ 1.1441755

Waxman MH, Smits LJM (1968) Electrical conductivities in oil bearing sands. Journal of the society of Petroleum Engineerins 8:107-122

Worthington PF (1993) The uses and abuses of the Archie equations. 1. The formation factor-porosity relationship. J Appl Geophys 30:215-228. doi:10.1016/09269851(93)90028-W

Yadav GS (1995) Relating hydraulic and geoelectric parameters of the Jayant aquifer, India. J Hydrol (Amst) 167:23-38. doi:10.1016/0022-1694(94)02637-Q

Yadav GS, Kumar R, Singh PN, Singh SC (1993) Geoelectrical soundings for aquifer characterization around Jayant colony-Singrauli, Sidhi District, MP. J Assoc Expl Geophysists XIV(3):123-131.

Yadav, G.S., and Abolfazli (1998) Geoelectrical sounding and their relationship to hydraulic parameters in semi-arid regions of Jalore, north-western India. J. Applied Geophysics, 39: 35-51. 


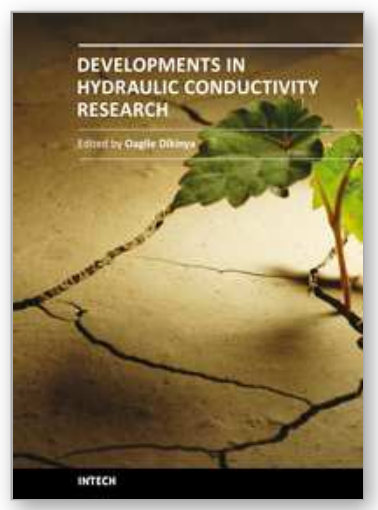

\author{
Developments in Hydraulic Conductivity Research \\ Edited by Dr. Oagile Dikinya
}

ISBN 978-953-307-470-2

Hard cover, 270 pages

Publisher InTech

Published online 28, February, 2011

Published in print edition February, 2011

This book provides the state of the art of the investigation and the in-depth analysis of hydraulic conductivity from the theoretical to semi-empirical models perspective as well as policy development associated with management of land resources emanating from drainage-problem soils. A group of international experts contributed to the development of this book. It is envisaged that this thought provoking book will excite and appeal to academics, engineers, researchers and University students who seek to explore the breadth and indepth knowledge about hydraulic conductivity. Investigation into hydraulic conductivity is important to the understanding of the movement of solutes and water in the terrestrial environment. Transport of these fluids has various implications on the ecology and quality of environment and subsequently sustenance of livelihoods of the increasing world population. In particular, water flow in the vadose zone is of fundamental importance to geoscientists, soil scientists, hydrogeologists and hydrologists and allied professionals.

\title{
How to reference
}

In order to correctly reference this scholarly work, feel free to copy and paste the following:

Mohamed Ahmed Khalil and Fernando A. Monterio Santos (2011). Influence of Degree of Saturation in the Electric Resistivity-Hydraulic Conductivity Relationship, Developments in Hydraulic Conductivity Research, Dr. Oagile Dikinya (Ed.), ISBN: 978-953-307-470-2, InTech, Available from:

http://www.intechopen.com/books/developments-in-hydraulic-conductivity-research/influence-of-degree-ofsaturation-in-the-electric-resistivity-hydraulic-conductivity-relationship

\section{INTECH}

open science | open minds

\section{InTech Europe}

University Campus STeP Ri

Slavka Krautzeka 83/A

51000 Rijeka, Croatia

Phone: +385 (51) 770447

Fax: +385 (51) 686166

www.intechopen.com

\section{InTech China}

Unit 405, Office Block, Hotel Equatorial Shanghai

No.65, Yan An Road (West), Shanghai, 200040, China

中国上海市延安西路65号上海国际贵都大饭店办公楼 405 单元

Phone: +86-21-62489820

Fax: $+86-21-62489821$ 
(C) 2011 The Author(s). Licensee IntechOpen. This chapter is distributed under the terms of the Creative Commons Attribution-NonCommercialShareAlike-3.0 License, which permits use, distribution and reproduction for non-commercial purposes, provided the original is properly cited and derivative works building on this content are distributed under the same license. 